\title{
Major Gene Resistance to Blackleg in Brassica napus Overcome Within Three Years of Commercial Production in Southeastern Australia
}

\author{
S. J. Sprague, CSIRO Plant Industry, GPO Box 1600, Canberra, ACT 2601 and School of Botany, The University of \\ Melbourne, Victoria 3010, Australia; S. J. Marcroft, Marcroft Grains Pathology, Grains Innovation Park, Horsham, \\ Victoria 3400, Australia; and H. L. Hayden and B. J. Howlett, School of Botany, The University of Melbourne, \\ Australia
}

\begin{abstract}
Sprague, S. J., Marcroft, S. J., Hayden, H. L., and Howlett, B. J. 2006. Major gene resistance to blackleg in Brassica napus overcome within three years of commercial production in southeastern Australia. Plant Dis. 90:190-198.

The infection by Leptosphaeria maculans of Brassica napus cultivars with major gene resistance derived from Brassica rapa subsp. sylvestris was studied in southeastern Australia. Following the commercial release of these cultivars in Australia in 2000, plants with stem cankers were first reported in 2002 at two geographically isolated regions in South Australia and New South Wales. In 2003, this study showed that the major gene resistance had been overcome in an area of approximately 50,000 ha in South Australia and in two fields in New South Wales (0.5 and 30 ha). There was no relationship between disease severity and incidence in 2003 and the proximity to the sites where resistance breakdown occurred in 2002. At some locations, the frequency of isolates able to overcome the $B$. rapa subsp. sylvestris-derived resistance had increased between 2002 and 2003. Isolates cultured from canola cultivars with either B. rapa subsp. sylvestrisderived resistance or polygenic resistance showed host specificity when inoculated onto cultivars with B. rapa subsp. sylvestris-derived or polygenic resistance, respectively. The most likely cause of the resistance breakdown was the rapid increase in frequency of $L$. maculans isolates virulent on this particular resistance source. The selection pressure leading to this increased frequency was probably mediated by the planting of cultivars harboring the major resistance gene in the same locations for a 3-year period, and the ability of the pathogen to produce large numbers of asexual and sexual spores.
\end{abstract}

Additional keywords: oilseed rape, Phoma lingam

Blackleg, caused by the pathogen Leptosphaeria maculans (anamorph = Phoma lingam (Tode:Fr.) Desmaz.), is one of the most important diseases of Brassica napus L. var. oleifera (Metzer) Sink. (canola, oilseed rape, and colza) worldwide $(13,34)$. The primary source of inoculum is airborne ascospores released from infected stubble following rainfall. In Australia, ascospore release begins after the first autumn rains and coincides with the emergence of new crops. Hyphae from germinating ascospores enter the cotyledons or leaves via stomata or wounds, initially colonizing spaces between the mesophyll cells (11). From the leaf, the fungus grows within the vascular tissue to the stem base where it becomes necrotrophic, causing a basal canker which results in reduced water and nutrient uptake, or plant death if necrosis is severe (12).

Host resistance to $L$. maculans has been identified at the seedling (leaf lesion) and

Corresponding author: S. J. Sprague

E-mail: Susan.Sprague@csiro.au

Accepted for publication 6 September 2005.

DOI: 10.1094/PD-90-0190

(C) 2006 The American Phytopathological Society adult (stem canker) growth stages. Resistance in the seedling and adult growth stages can be under the same $(15,27,36)$ or different genetic control $(3,25)$, and can be either monogenic (single major gene) or polygenic (quantitative trait loci). Genefor-gene interactions have been described whereby resistance genes in the host (expressed in cotyledons) are matched by complementary avirulence genes in the fungus (1,2). Until recently, Australian cultivars relied on polygenic adult plant resistance, which provides protection only against stem canker while leaves remain susceptible to infection (20). Hereafter in this article, these cultivars are described as "polygenic" cultivars. The stem canker phase of the disease is the most important because this symptom is associated with yield loss (22). The term "resistance breakdown" is used in this article to refer to the ability of isolates in the field to form stem cankers on cultivars with $B$. rapa subsp. sylvestris-derived resistance.

To improve resistance of B. napus cultivars to L. maculans, related Brassica spp. have been screened to provide sources of resistance $(8,10,20,28,30)$. Due to the presence of similar genomes in different Brassica spp., resistance loci identified in one species can be introgressed into $B$. napus (33). The three amphidiploid species, B. napus (AACC), B. juncea (AABB), and $B$. carinata $(\mathrm{BBCC})$ are derived from crosses between the three diploid species, $B$. oleracea (AA), B. nigra (BB), and $B$. rapa (CC) as described by the Triangle of U (33). Crouch and colleagues (8) produced a synthetic $B$. napus line by crossing $B$. oleracea subsp. alboglabra with an accession of $B$. rapa subsp. sylvestris that had a high level of resistance to $L$. maculans. The $\mathrm{F}_{1}$ progeny resulting from a cross between the synthetic line and a $B$. napus line was highly resistant to $L$. maculans when tested under field conditions in Australia and England (8). This resistance derived from $B$. rapa subsp. sylvestris (hereafter referred to as sylvestris-derived resistance) was then incorporated successfully into $B$. napus cultivars agronomically suited to Australia, resulting in lines with an extremely high degree of resistance to L. maculans. Resistance was conferred by a single dominant gene $($ LepR $3 ; 15,35)$ and provided the plant with almost complete protection from infection of the leaf by inhibiting spore germination and mycelial growth, hence reducing the formation of stem canker $(18,31)$. A number of cultivars containing this source of resistance were released commercially in 2000 for different Australian environments.

In 2002, canker symptoms not previously observed on cultivars with sylvestrisderived resistance were identified at two canola trial sites in southeastern Australia: Cudal in New South Wales $\left(148^{\circ} 45^{\prime} \mathrm{E}\right.$, $\left.33^{\circ} 17^{\prime} \mathrm{S}\right)$ and the Lower Eyre Peninsula in South Australia ( $\left.135^{\circ} 43^{\prime} \mathrm{E}, 34^{\circ} 15^{\prime} \mathrm{S}\right)(9)$. In addition, Li et al. (19) identified isolates of L. maculans in Western Australia capable of attacking these cultivars. The locations in South Australia, New South Wales, and Western Australia each were separated by more than 1,000 km (Fig. 1). The initial site in 2002 on the Lower Eyre Peninsula was an area of 0.5 ha. In 2003, nearly every field sown with cultivars with sylvestris-derived resistance within the 50,000ha canola production area was severely affected and, in 2004, no cultivars with sylvestris-derived resistance were grown in the Lower Eyre Peninsula region.

Cultivars with sylvestris-derived resistance released commercially in 2000 were highly resistant to $L$. maculans, with an Australian Blackleg Rating (ABR) of be- 
tween 8.0 and 9.0 , where a rating of 1.0 is highly susceptible and 9.0 is highly resistant (Canola Association of Australia. Anonymous. 2000). The ABR is a national system that ranks all commercially released $B$. napus cultivars according to their survival due to stem canker resistance in experiments conducted across Australia at sites with high levels of $L$. maculans inoculum (20). In 2004, these cultivars were still rated as highly resistant but a warning that they may be highly susceptible in some areas was published with the ratings. These warnings reflected the fact that none of the trial sites used to determine the 2004 $\mathrm{ABR}$ values were in regions where the breakdown of sylvestris-derived resistance occurred in 2003.

Breakdown of major gene resistance in $B$. napus to L. maculans has been reported previously in France. In a wide-scale survey of commercial fields in France between 1990 and 2000, 1,011 isolates of $L$. maculans were assessed for the presence of three avirulence genes (AvrLml, AvrLm2, and AvrLm4; 29). The proportion of isolates harboring AvrLml declined rapidly in the years after the 1998-99 season, when cultivars with the corresponding resistance gene $R l m l$ accounted for $43.7 \%$ of the acreage sown to B. napus in France. In a second study, $B$. napus lines with major gene resistance introgressed from either $B$. juncea or $B$. nigra were tested in the field to determine the durability of the resistance source (5). The lines were sown into stubble of the resistant lines and infected susceptible lines collected from the previous year. Resistance in lines containing major gene resistance introgressed from $B$. juncea was overcome in 3 years, whereas lines with resistance derived from $B$. nigra remained effective after 4 years.

In this article, we report the findings of a survey aimed at determining (i) the distribution of L. maculans isolates able to attack B. napus lines with sylvestrisderived resistance and (ii) the prevalence of diseased plants in field experiments and commercial crops of cultivars with sylvestris-derived or polygenic resistance in southeastern Australia. We also report changes in host specificity of the pathogen population in response to sowing of cultivars with sylvestris-derived resistance. The results are discussed in relation to the durable deployment of different sources of resistance to $L$. maculans.

\section{MATERIALS AND METHODS}

Survey of commercial fields of $B$. napus cultivars with sylvestris-derived resistance. A survey of cultivars with sylvestris-derived resistance (Surpass 400, Surpass 603CL, Surpass 501TT, and Hyola 60) was conducted in commercial crops and field experiments in 2003 and 2004 (Fig. 1). In 2003, the area within a 100-km radius of the sites at Cudal in New South Wales and Lower Eyre Peninsula in South
Australia, where stem cankers first were observed in cultivars with sylvestrisderived resistance in 2002, was surveyed. In addition, commercial fields in canolaproducing regions of Victoria, southern New South Wales, and around Bordertown in South Australia were examined. In 2004, the survey was conducted in South Australia, Victoria, and southern New South Wales.

In 2003, crops at several distances from sites where stem cankers first were observed in plants of cultivars with sylvestrisderived resistance in 2002 were examined. Commercial crops of cultivars with sylvestris-derived resistance were identified within a $100-\mathrm{km}$ radius of the site on Lower Eyre Peninsula in South Australia and Cudal in New South Wales (Fig. 1). In all, 31 fields were assessed on Lower Eyre Peninsula and 33 fields were assessed near Cudal. Both of these areas are intensive cropping zones, with canola grown in fields every 2 to 4 years in rotation with cereals and, sometimes, a grain legume. Based on the proximity of crops to the sites where stem cankers first were observed in 2002, fields were grouped into categories: 0 to $5 \mathrm{~km}, 5$ to $10 \mathrm{~km}, 10$ to 20 $\mathrm{km}, 20$ to $30 \mathrm{~km}, 30$ to $50 \mathrm{~km}$, or 50 to 100 $\mathrm{km}$. This experiment was not repeated in 2004 because cultivars with sylvestrisderived resistance were no longer widely grown in either South Australia or New South Wales after results from the 2003 survey were communicated to growers.

In 2003 and 2004, a survey was carried out in canola-producing areas of South Australia, Victoria, and New South Wales to establish the prevalence of isolates capable of causing disease in cultivars with sylvestris-derived resistance (Fig. 1). In all, 99 sites were assessed in 2003 (including those sites at Lower Eyre Peninsula and Cudal described above) and 52 sites in 2004. In 2003, the majority of sites assessed were commercial fields of cultivars with sylvestris-derived resistance. Sites were distributed across Victoria and New South Wales but were only located at the Lower Eyre Peninsula and Bordertown in South Australia. In 2004, the disease severity and incidence in cultivars with either polygenic resistance or sylvestris-derived resistance were assessed at experimental sites. The cv. Beacon (ABR 6.0) with polygenic resistance and cv. Surpass 501TT (ABR 8.5) with major gene sylvestrisderived resistance were examined at most sites. Where these cultivars were not present, cultivars with polygenic and sylvestris-derived resistance with an ABR similar to cvs. Beacon and Surpass 501TT were assessed instead. The size of sites ranged from 0.5 ha for some experimental sites to over 100 ha for commercial crops.

The severity and incidence of L. maculans infection was assessed on 60 or 100 mature plants per site just prior to windrowing. Plants assessed in commercial fields were chosen by walking a "W" transect, taking four paces and selecting the third plant from the right foot (15 or 25 plants per leg of the "W"). Plants assessed in trial plots were selected by taking 20 consecutive plants in the same row beginning at least $1 \mathrm{~m}$ from the end of the plot. Three replicate plots were assessed at each trial site. Plants were cut transversely at the crown and then visually assessed for blackleg symptoms. Each plant was scored as having $0,5,10,20,30,40,50,60,70$, 80,90 , or $100 \%$ internal infection (disease severity; 22). The average disease severity and incidence of plants with disease severity $\geq 5 \%$ was then calculated for each field and trial site.

Collection of $L$. maculans isolates. Isolates of L. maculans derived from single ascospores were collected from infected canola stubble from 19 fields at 13 different locations in southeastern Australia during a 3-year period (2002 to 2004; Fig. 1; Table 1). L. maculans is a heterothallic fungus with two mating types; therefore, the ascospore-derived isolates cultured from stubble in one year (e.g., 2002) originate from sexual recombination between isolates that infected the crop in the previous season (e.g., 2001).

Following the commercial release of cultivars with sylvestris-derived resistance in 2000 , isolates were cultured from the stubble of several cultivars collected in 2002 and 2003 from L. maculans disease nurseries and commercial fields in Victoria, New South Wales, and South Australia to monitor the presence and frequency of isolates able to overcome the sylvestrisderived resistance in different areas (Table 1). These sites were representative of canola-producing areas in Australia. Isolates collected in 2003 and 2004 were tested for virulence concurrently with the field surveys. After the breakdown of the sylvestris-derived resistance during the 2003 growing season, isolates were collected from the stubble of cultivars with polygenic or sylvestris-derived resistance from commercial fields in Victoria and South Australia in 2004. The ability of these isolates to attack both types of resistance was then tested. All stubble collected in 2004 from South Australia was from areas where the breakdown of cultivars with sylvestris-derived resistance had occurred in 2003.

Stubble pieces bearing L. maculans pseudothecia were wetted and suspended over water agar plates (20 g of agar per liter of water) for $2 \mathrm{~h}$ for ascospore discharge. Several single ascospores of $L$. maculans per stubble piece were collected. Individual ascospores were transferred to Campbell's V8 juice agar plates $(100 \mathrm{ml}$ of V8 juice and $20 \mathrm{~g}$ of agar per liter of water, $\mathrm{pH} 6$ ) and incubated at $20^{\circ} \mathrm{C}$ with $12 \mathrm{~h}$ of light. Isolates were stored in sterile water and on dried cellulose discs at $20^{\circ} \mathrm{C}$ with silica gel. 
Virulence of $\boldsymbol{L}$. maculans isolates. Cotyledon test. Isolates collected from 2002 and 2003 stubble were tested for pathogenicity on the cotyledons of $B$. napus cv. Surpass 400 (Table 1). This test provides a reliable indication of the ability of an isolate to form stem cankers on cultivars with sylvestris-derived resistance (16). The total number of isolates tested from 2002 stubble was 122 (35 from South Australia, 26 from Victoria, and 61 from New South Wales). In all, 104 isolates from 2003 stubble were tested (49 from South Australia, 40 from Victoria, and 15 from New South Wales). A well-characterized Australian isolate, IBCN 18 (formerly named M1), collected in 1986, was included as a control. Isolates were each inoculated onto 12 plants grown from commercial seed of cv. Surpass 400 at 10 days after sowing as described previously (27). Plants were grown in a glasshouse maintained at a constant temperature of $22^{\circ} \mathrm{C}$. Pycnidiospores were harvested from 12-day-old cultures grown on $10 \%$ V8 agar as described above. The plates were flooded with sterile water, then scraped with a scalpel to liberate pycnidia. After $1 \mathrm{~h}$, the pycnidiospore suspension was filtered through Miracloth and the concentration of spores adjusted. Pycnidiospore suspensions of $1 \times 10^{7}$ spores $/ \mathrm{ml}$ were applied as a 10- $\mu$ l droplet onto four pinprick wounds on the cotyledons (total of 48 inoculations per isolate). The 12 plants per punnet were inoculated with one isolate and placed into a high humidity container with free water at $22^{\circ} \mathrm{C}$. After $48 \mathrm{~h}$, the droplets of inoculum had dried up and plants were removed from the humidity chamber. Punnets were watered carefully to avoid cross-contamination of isolates. To allow full expansion of the cotyledons, developing true leaves were removed.

Disease was rated between 12 and 14 days post inoculation with a 0 -to-9 scale as described previously by Koch et al. (14), where $0=$ no darkening around wounds; 1 $=$ limited blackening around wounds, lesion diameter 0.5 to $1.5 \mathrm{~mm} ; 3=$ dark necrotic lesions, 1.5 to $3 \mathrm{~mm} ; 5=$ dark lesions, 3 to $6 \mathrm{~mm}$, brownish on lower surface; $6=$ as in 5 , but less necrotic; $7=$ gray-green lesions of limited size or large necrotic lesions; $8=$ spreading graylesions with no or few pycnidia; and $9=$ large gray-green lesions with profuse

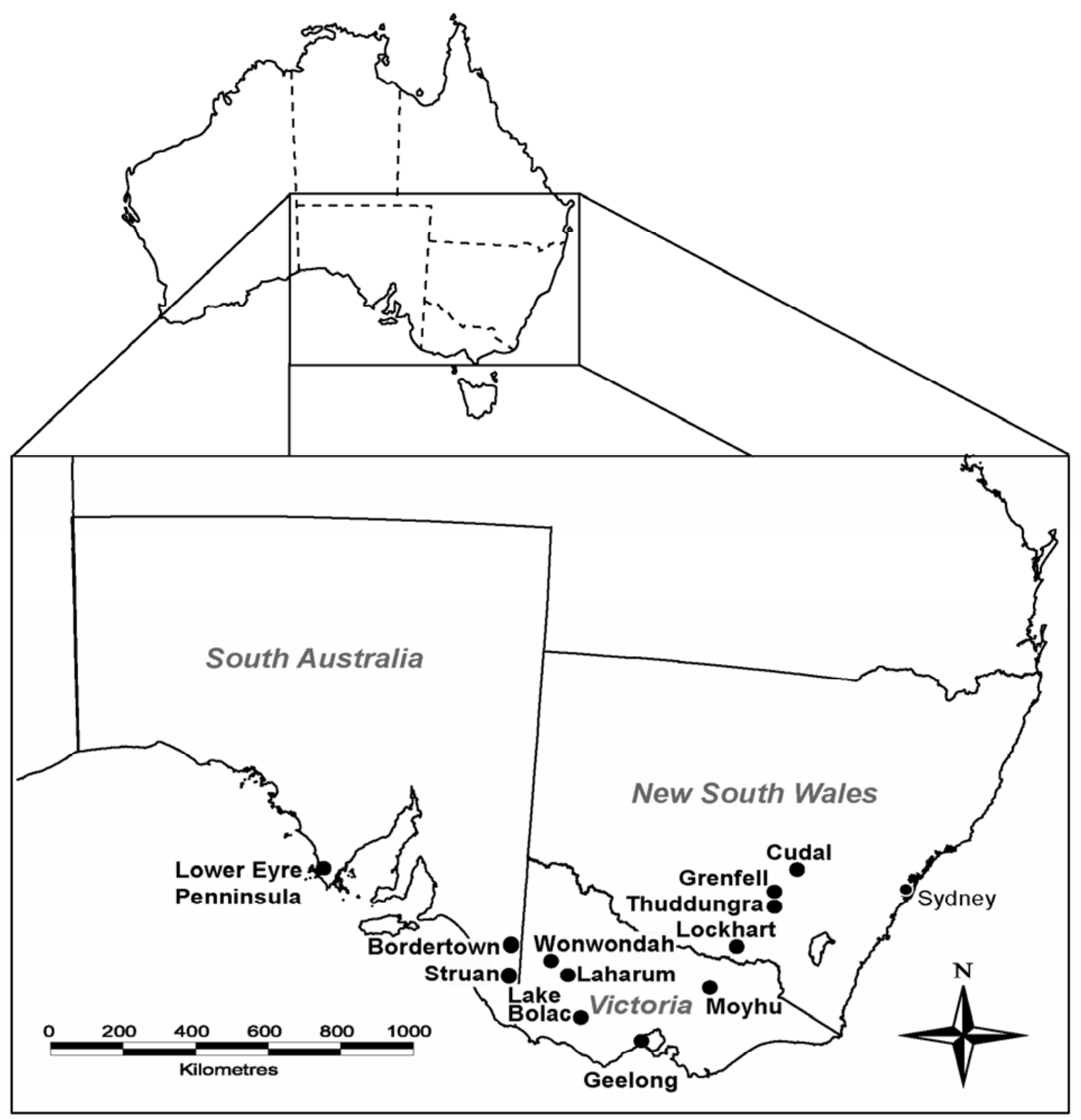

Fig. 1. Sites in southeastern Australia from which Leptosphaeria maculans isolates were collected, as well as where cankers were first observed on stems of blackleg-affected cultivars with Brassica rapa subsp. sylvestris-derived resistance (Lower Eyre Peninsula, South Australia, and Cudal, New South Wales). 
sporulation. Lesions were not scored for plants that had senesced by 12 to 14 days post inoculation when disease was scored. Isolates were classified as having either low (cotyledon score 0 to 2 ), moderate (2 to 4 ), high (4 to 6), or very high (6 to 9) cotyledon scores (14). The percentage of isolates in each category was then determined for each state (South Australia, New South Wales, and Victoria) for each year.

Stem test. To determine whether isolates exhibited host specificity in their ability to develop stem cankers in cultivars with major gene sylvestris-derived resistance or cultivars with polygenic resistance, isolates collected from South Australia and Victoria from stubble in 2004 were tested for the development of stem canker in cv. Beacon (ABR 6.5) with polygenic resistance, cv. Surpass 400 (ABR 9.0), and cv. Q2 (ABR $1.0)$, which was used as a susceptible control. In all, 33 isolates were tested, 18 collected from stubble of polygenic cultivars in Victoria and 15 from stubble of cultivars with sylvestris-derived resistance in South Australia (Table 1). Twenty-eight days after sowing, plants at the one-leaf stage were sprayed with a pycnidiospore suspension $\left(1 \times 10^{7}\right.$ spores $/ \mathrm{ml}$ with $0.05 \%$ Tween
20) until run-off. Pycnidiospore suspension was collected as described above. Six individual plants of each cultivar were inoculated with each isolate. Plants were then placed in a humidity chamber for $48 \mathrm{~h}$ before transfer to a shade house, where they were fertilized and watered as required. Severity of stem canker development was assessed 18 weeks postinoculation by cutting the plant at the crown and scoring disease severity using a 0 to $100 \%$ scale as described above.

Statistical analyses. Stem canker severity data and disease incidence data collected from the survey of commercial crops were square-root transformed and arcsin transformed, respectively, prior to analysis (22). Analyses were performed using REML, the algorithm in Genstat version 6.1 (26) for unbalanced data sets. All values presented in tables and figures are of untransformed data.

\section{RESULTS}

Breakdown of sylvestris-derived resistance in the field. There were no significant differences between the severity and incidence of blackleg recorded in cultivars with sylvestris-derived resistance at dis- tances up to $100 \mathrm{~km}$ from the original sites where cankers first were observed in 2002 in either the Cudal or Lower Eyre Peninsula regions (data not shown). However, there was a significant difference in the level of disease between the two regions. High levels of disease were recorded on Lower Eyre Peninsula at sites up to 100 $\mathrm{km}$ from the original site, with an average disease severity of 60 and incidence of 94\% across the 31 fields surveyed. At a distance of 0 to $5 \mathrm{~km}$ from the Lower Eyre Peninsula site, the disease severity was 63 and the incidence was $97 \%$ and, at 50 to $100 \mathrm{~km}$, the disease severity was 47 and the incidence was $87 \%$. In contrast, around Cudal in New South Wales, the average disease severity across the 33 fields surveyed was 2 and the incidence was $10 \%$. Disease severity was less than 5 and the incidence below $20 \%$ at all distances.

The severity and incidence of blackleg recorded in the survey of cultivars with sylvestris-derived resistance differed between states in 2003 and 2004 (Table 2). In South Australia, disease severity was constant between 2003 and 2004 but disease incidence declined. In both years, all sites examined in South Australia had infected

Table 1. Source of Leptosphaeria maculans isolates from southeastern Australia ${ }^{\mathrm{x}}$

\begin{tabular}{|c|c|c|c|c|}
\hline Location & $\begin{array}{c}\text { Year stubble } \\
\text { collected }\end{array}$ & Brassica napus cultivar & $\begin{array}{l}\text { ABR of cultivar } \\
\text { in year grown }\end{array}$ & No. of isolates tested \\
\hline Struan, South Australia & 2002 & Polygenic and sylvestris-derived ${ }^{\mathrm{z}}$ & .. & 35 \\
\hline Wonwondah, Victoria, & 2002 & ATR-Beacon & 6.0 & 7 \\
\hline Lake Bolac, Victoria, & 2002 & TI1 Pinnacle & 5.5 & 19 \\
\hline Farm 1, Thuddungra, New South Wales & 2002 & TI1 Pinnacle & 5.5 & 27 \\
\hline Farm 2, Thuddungra, New South Wales & 2002 & ATR-Grace & 6.5 & 34 \\
\hline Struan, South Australia & 2003 & Polygenic and sylvestris-derived & $\ldots$ & 34 \\
\hline Lower Eyre Peninsula, South Australia & 2003 & Polygenic and sylvestris-derived & $\ldots$ & 15 \\
\hline Wonwondah, Victoria & 2003 & ATR-Beacon & 6.0 & 12 \\
\hline Lake Bolac, Victoria & 2003 & TI1 Pinnacle & 6.0 & 28 \\
\hline Lockhart, New South Wales & 2003 & ATR-Beacon & 6.0 & 8 \\
\hline Grenfell, New South Wales & 2003 & TI1 Pinnacle & 6.0 & 7 \\
\hline Wonwondah, Victoria & 2004 & ATR-Grace & 6.5 & 3 \\
\hline Laharum, Victoria & 2004 & TI1 Pinnacle & 5.5 & 3 \\
\hline Geelong, Victoria & 2004 & TI1 Pinnacle & 5.5 & 4 \\
\hline Moyhu, Victoria & 2004 & ATR-Grace & 6.5 & 5 \\
\hline Bordertown, South Australia & 2004 & Ag-Emblem & 7.0 & 3 \\
\hline Lower Eyre Peninsula, South Australia & 2004 & Surpass 400 & 8.5 & 5 \\
\hline Farm 1, Bordertown, South Australia & 2004 & Surpass 603CL & 8.5 & 5 \\
\hline Farm 2, Bordertown, South Australia & 2004 & Surpass 603CL & 8.5 & 5 \\
\hline
\end{tabular}

${ }^{x}$ Pathogenicity of isolates collected in 2002 and 2003 was tested on cotyledons, while isolates collected in 2004 were tested for ability to cause stem cankers.

y ABR = Australian Blackleg Rating; all commercially released cultivars are ranked according to their survival in trials conducted across Australia, with 1.0 being highly susceptible and 9.0 being highly resistant.

${ }^{\mathrm{z}}$ Cultivar from which isolates were collected is unknown.

Table 2. Presence of blackleg in Brassica napus cultivars with B. rapa subsp. sylvestris-derived resistance at sites in the canola-producing areas of South Australia (SA), Victoria (Vic), and New South Wales (NSW) in 2003 and 2004

\begin{tabular}{|c|c|c|c|c|c|c|c|c|}
\hline \multirow[b]{2}{*}{ State } & \multicolumn{4}{|c|}{2003} & \multicolumn{4}{|c|}{2004} \\
\hline & No. of sites & Infected $^{y}$ & Severity $^{z}$ & Incidence $(\%)^{\mathrm{z}}$ & No. of sites & Infected $^{y}$ & Severity $^{z}$ & Incidence $(\%)^{\mathrm{z}}$ \\
\hline$\overline{\mathrm{SA}}$ & 33 & 33 & $60.0 \pm 2.7 \mathrm{a}$ & $94.1 \pm 1.2 \mathrm{c}$ & 15 & 15 & $48.7 \pm 9.0 \mathrm{a}$ & $66.0 \pm 9.5 \mathrm{~d}$ \\
\hline NSW & 47 & 44 & $1.7 \pm 0.7 \mathrm{a}$ & $8.8 \pm 2.3 \mathrm{c}$ & 16 & 14 & $5.8 \pm 1.6 \mathrm{~b}$ & $34.4 \pm 6.1 \mathrm{~d}$ \\
\hline Vic & 19 & 19 & $4.1 \pm 0.9 \mathrm{a}$ & $19.6 \pm 3.5 \mathrm{c}$ & 21 & 18 & $3.6 \pm 0.6 \mathrm{a}$ & $14.6 \pm 2.0 \mathrm{c}$ \\
\hline Mean of all states & 99 & 96 & $22.3 \pm 3.0$ & $40.3 \pm 4.2$ & 52 & 47 & $18.6 \pm 4.2$ & $36.9 \pm 4.7$ \\
\hline
\end{tabular}

y Infected sites (Infected) are those that had $\geq 1$ plant with blackleg disease symptoms in the stem.

${ }^{\mathrm{z}}$ Severity is the area of the stem cross-section with disease symptoms (0 to $100 \%$ ) and incidence is the percentage of plants with disease severity $\geq 5 \%$ per site. Values are the average \pm standard error for infected sites. Disease severity values ( $a$ or $b$ ) and disease incidence values (c or d) followed by the same letter across a row (i.e., between years) are not significantly different at $P=0.05$. 
plants and also high disease severity. All sites in South Australia in 2003 had over $50 \%$ of plants infected, whereas 11 of 15 of the sites had more than $50 \%$ of plants infected in 2004. The level of disease recorded in Victoria remained constant, with an average severity of 3.7 and incidence of $17.2 \%$ over the 2 years. In Victoria, one
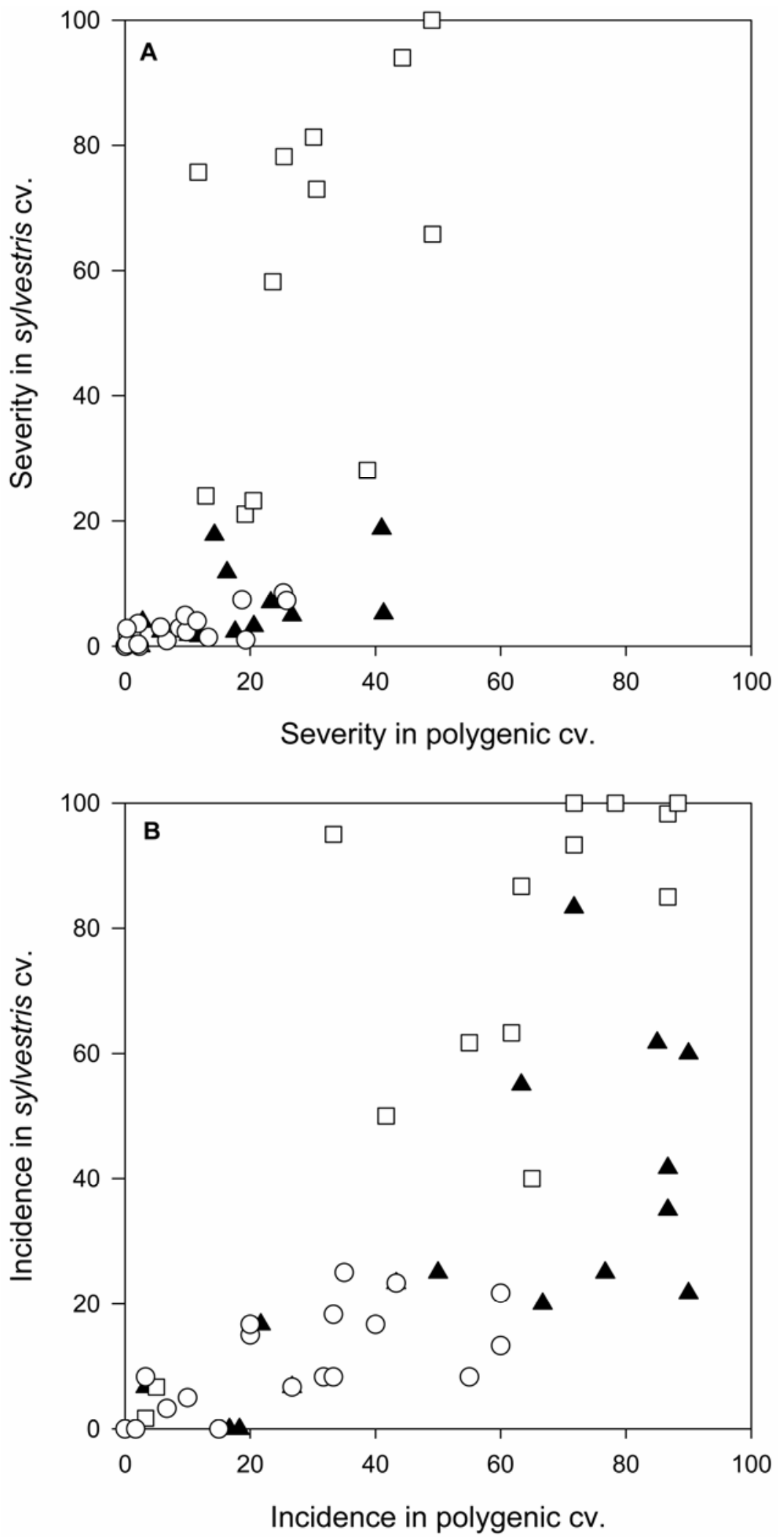

Fig. 2. A, Blackleg severity and $\mathbf{B}$, incidence in Brassica napus cultivars with polygenic or B. rapa subsp. sylvestris-derived resistance at sites in Victoria $(\bigcirc)$, South Australia $(\square)$, and New South Wales $(\boldsymbol{\Delta})$ in 2004. Each point represents data collected from one site. Severity is the area of the stem crosssection with disease symptoms ( 0 to $100 \%$ ) and incidence is the percentage of plants with disease severity $\geq 5 \%$ per site.

site recorded over $50 \%$ of plants infected but the mean disease severity was only 5.2. In New South Wales, the severity of disease remained low; however, the incidence of blackleg increased from $8.8 \%$ in 2003 to $34.4 \%$ in 2004. In 2003, one site had $92 \%$ of plants infected, with a mean severity of 31.5 , while another site had $47 \%$ of plants infected, with a mean severity of 10.5 . Both of these fields had been sown with cultivars with sylvestris-derived resistance in adjacent fields for three consecutive seasons. In 2004, four sites had over 50\% of plants infected; however, the disease severity was less than 20 at each site (data not shown).

When blackleg severity was compared in cultivars with polygenic or sylvestrisderived resistance at the same site in 2004, the disease severity differed between sites and states (Fig. 2A). At all Victorian sites, disease severity was low, with an average severity of less than 25 in the polygenic cultivar and less than 10 in the cultivar with sylvestris-derived resistance. A similar trend was observed at New South Wales sites, with disease severity higher in the polygenic compared with the cultivar with sylvestris-derived resistance. Two sites in South Australia had an average disease severity of less than 2.0 in both the polygenic cultivar and the cultivar with sylvestris-derived resistance; however, at the majority of the remaining sites, the disease severity was greater than 20 in the cultivar with polygenic resistance and greater than 55 in the cultivar with sylvestris-derived resistance.

The incidence of plants with blackleg in cultivars with polygenic and sylvestrisderived resistance followed a trend similar to that of disease severity, with the highest levels observed at sites in South Australia and the lowest at Victorian sites (Fig. 2B). In Victoria, disease incidence in the polygenic cultivar ranged from 2 to $60 \%$ and 0 to $23 \%$ in the cultivar with sylvestrisderived resistance. As in Victoria, most sites in New South Wales had a higher incidence of blackleg in the polygenic cultivar than in the cultivar with sylvestrisderived resistance, although the range was greater. The incidence of blackleg recorded at sites in South Australia was similar in cultivars with polygenic or sylvestrisderived resistance, and both cultivars had an incidence greater than $50 \%$ at the majority of sites.

Virulence of $\boldsymbol{L}$. maculans isolates. The frequency of $L$. maculans isolates able to cause high and very high levels of disease on the cotyledons of Surpass 400 differed between states, with a shift in frequency observed from 2002 to 2003 for isolates from South Australia and Victoria (Fig. 3). The percentage of isolates collected from South Australia causing high and very high disease scores increased from 14.3 to $38.8 \%$ and 0 to $16.3 \%$, respectively. There was no change in the frequency of isolates 
causing moderate disease scores but a large decline from 48.6 to $8.2 \%$ in isolates causing low disease scores. In Victoria, there was a similar increase in the proportion of isolates causing very high disease scores. During the 2 years, isolates from New South Wales showed a similar spectrum of disease scores on cotyledons of cv. Surpass 400. No New South Wales isolates gave very high disease scores. Isolate IBCN 18 gave medium scores in both 2002 (3.51 \pm 0.19$)$ and $2003(3.19 \pm 0.23)$, and also formed stem lesions on cv. Surpass 400 (data not shown).

Isolates collected from the stubble of cultivars with polygenic or sylvestrisderived resistance in 2004 showed host specificity when inoculated onto cultivars with polygenic or sylvestris-derived resistance and scored for stem canker severity (Fig. 4). Most isolates from stubble of polygenic cultivars caused more severe stem symptoms on the cvs. Q2 and Beacon than on Surpass 400, whereas isolates from stubble of cultivars with sylvestris-derived resistance caused more severe canker symptoms on Surpass 400 than on Q2 and Beacon (Fig. 4). The isolates cultured from stubble of cultivars with polygenic or sylvestris-derived resistance both caused very severe disease on cv. Q2 (severities of 98.5 \pm 0.7 and $89.1 \pm 3.3$, respectively), with most plants dead prior to maturity. On the moderately resistant $\mathrm{cv}$. Beacon, isolates from stubble of polygenic cultivars had an average disease severity of $70.0 \pm 5.9$, whereas isolates from stubble of cultivars with sylvestris-derived resistance had an average disease severity of $36.2 \pm 6.9$. In contrast, the average disease severity of isolates from cultivars with polygenic or sylvestris-derived resistance inoculated on cv. Surpass 400 was $19.7 \pm 5.4$ and $89.3 \pm$ 5.2 , respectively.

\section{DISCUSSION}

Our survey data show a significant decrease in efficacy of the major gene resistance to $L$. maculans derived from $B$. rapa subsp. sylvestris in some areas of southeastern Australia. This breakdown of resistance has been rapid, as in the years prior to our study, cultivars with sylvestrisderived resistance were highly resistant to the development of stem canker (31). The breakdown of major gene resistance described in this article appears to be more dramatic than the breakdown of resistance conferred by the Rlml gene in winter $B$. napus in France, which was widespread rather than limited to particular regions (29). This is not surprising, given that the temperate climate in which B. napus is grown in Australia allows for a high degree of recombination in the fungus during summer and for production of large amounts of ascospore inoculum. The temperate conditions and long growing period for canola also allow for more severe disease development (32). Another explana- tion for the large yield losses and very rapid resistance breakdown in Australia is that the general level of polygenic resistance of the Australian spring B. napus cultivars into which the sylvestris-derived resistance was introduced may have been less than that of the European winter $B$. napus cultivars, leading to severe losses when the resistance source was overwhelmed. Isolates of $L$. maculans able to overcome the sylvestris-derived resistance were collected from cultivars with sylvestris-derived resistance in Western Australia in 2001 (19), and also in 2002 and 2004 (17). However, results from field surveys of disease severity in Western Australia have not been published and severe yield losses were not reported until 2004 (W. Smith, Agronomic Acumen, Western Australia, personal communication).

Prior to 2003, cultivars with sylvestrisderived resistance were rated highly resistant, with an ABR of between 8.0 and 9.0. Very few leaf lesions or stem cankers were observed on cultivars with sylvestrisderived resistance (31); however, the pathogen was isolated from within infected stems at two field experiments in New South Wales in 2002 (J. Kirkegaard, CSIRO Plant Industry, personal communication). Indeed, Marcroft et al. (21) found that stubble of cultivars with sylvestrisderived resistance collected in December 2001 hosted pseudothecia and released ascospores, albeit at a much lower frequency than polygenic cultivars, suggesting that some infection of plants had occurred. The reduction in pseudothecia and subsequent ascospore release from the stubble of cultivars with sylvestris-derived resistance suggest strong selection for isolates able to overcome the sylvestrisderived resistance. The spores produced from these isolates infect the following crop and would compose a large proportion of the pathogen population in areas where the cultivars with sylvestris-derived resistance were widely grown. This may be the reason for the sudden and severe breakdown in areas such as Lower Eyre Peninsula, where cultivars with sylvestrisderived resistance constituted a large proportion of the area sown to canola.

Isolates of $L$. maculans able to overcome the sylvestris-derived resistance were most likely widespread in the Australian population prior to the commercial release of cultivars with sylvestris-derived resistance in 2000 . This is suggested by (i) the presence of isolates able to cause moderate to severe lesions on the cotyledons of cv. Surpass 400, which has sylvestris-derived resistance, in stubble of $B$. napus crops grown in locations across three states in 2001; (ii) the detection of disease in cultivars with sylvestris-derived resistance in geographically distant areas; and (iii) the lack of a relationship between proximity to the sites where the breakdown was first reported in 2002 and the level of disease recorded in crops with sylvestris-derived resistance up to $100 \mathrm{~km}$ away in 2003 . Indeed, isolates collected from B. napus in the early 1970s were able to form leaf lesions on cv. Surpass 400 (17), and the control isolate (IBCN 18) used in the cotyledon testing, which was collected in 1986, forms leaf lesions and stem cankers on cv. Surpass 400 (H. L. Hayden and B. J. Howlett, data not shown).

The initial increase in area sown to cultivars with sylvestris-derived resistance

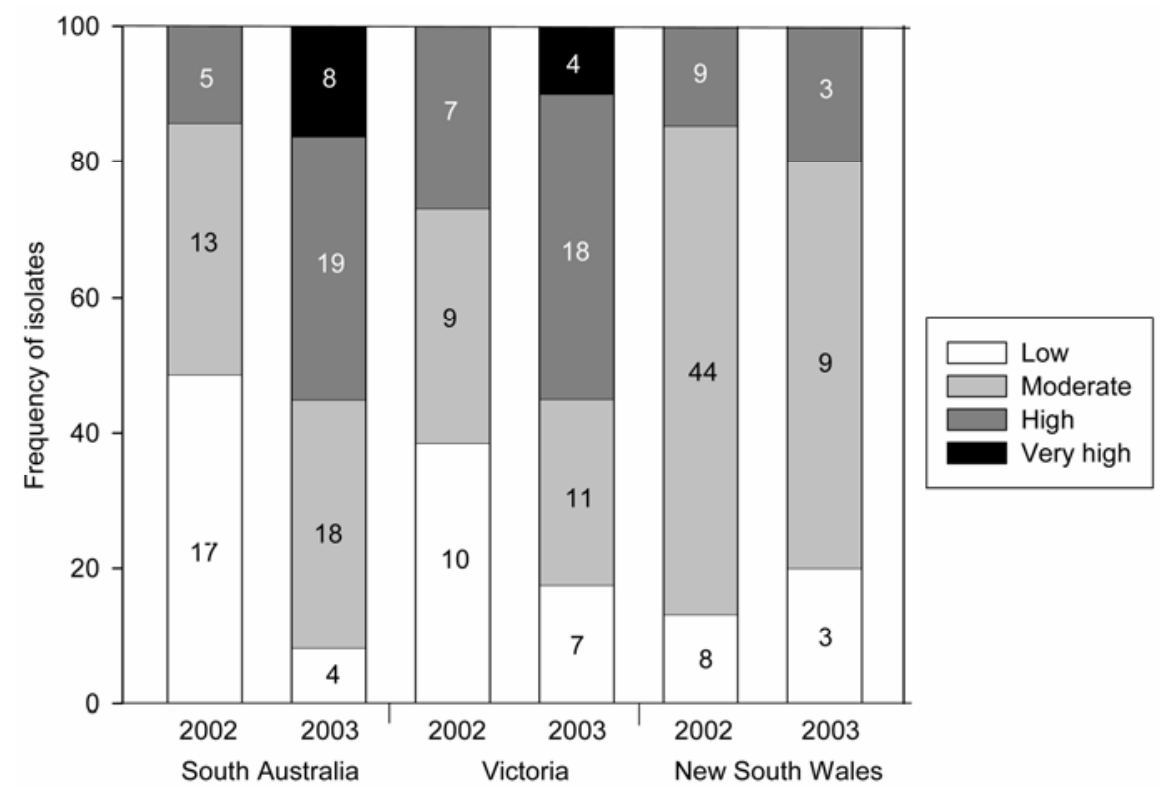

Fig. 3. Pathogenicity of Leptosphaeria maculans isolates collected in 2002 and 2003 from Victoria, South Australia, and New South Wales able to cause disease on Brassica napus cv. Surpass 400. Symptoms are classed as low, moderate, high, or very high depending on the mean lesion score based upon the lesion descriptions of Koch et al. (14). The number of isolates used to calculate the frequency is shown in each bar. 
and subsequent selection of isolates able to overcome the resistance in these crops resulted in a shift in the pathogen population. In the locations where the breakdown was most severe in 2003, cultivars with sylvestris-derived resistance were grown intensively during the previous seasons, thereby creating strong pressure to select those isolates capable of overcoming the resistance. Evidence of a shift in the pathogen population was observed in the increase in frequency from 2002 to 2003 of $L$. maculans field isolates able to cause disease on the cotyledons of a cultivar with sylvestris-derived resistance. Many of the most damaging and dangerous pathogens undergo a combination of sexual and asexual reproduction, termed a "mixed" repro-
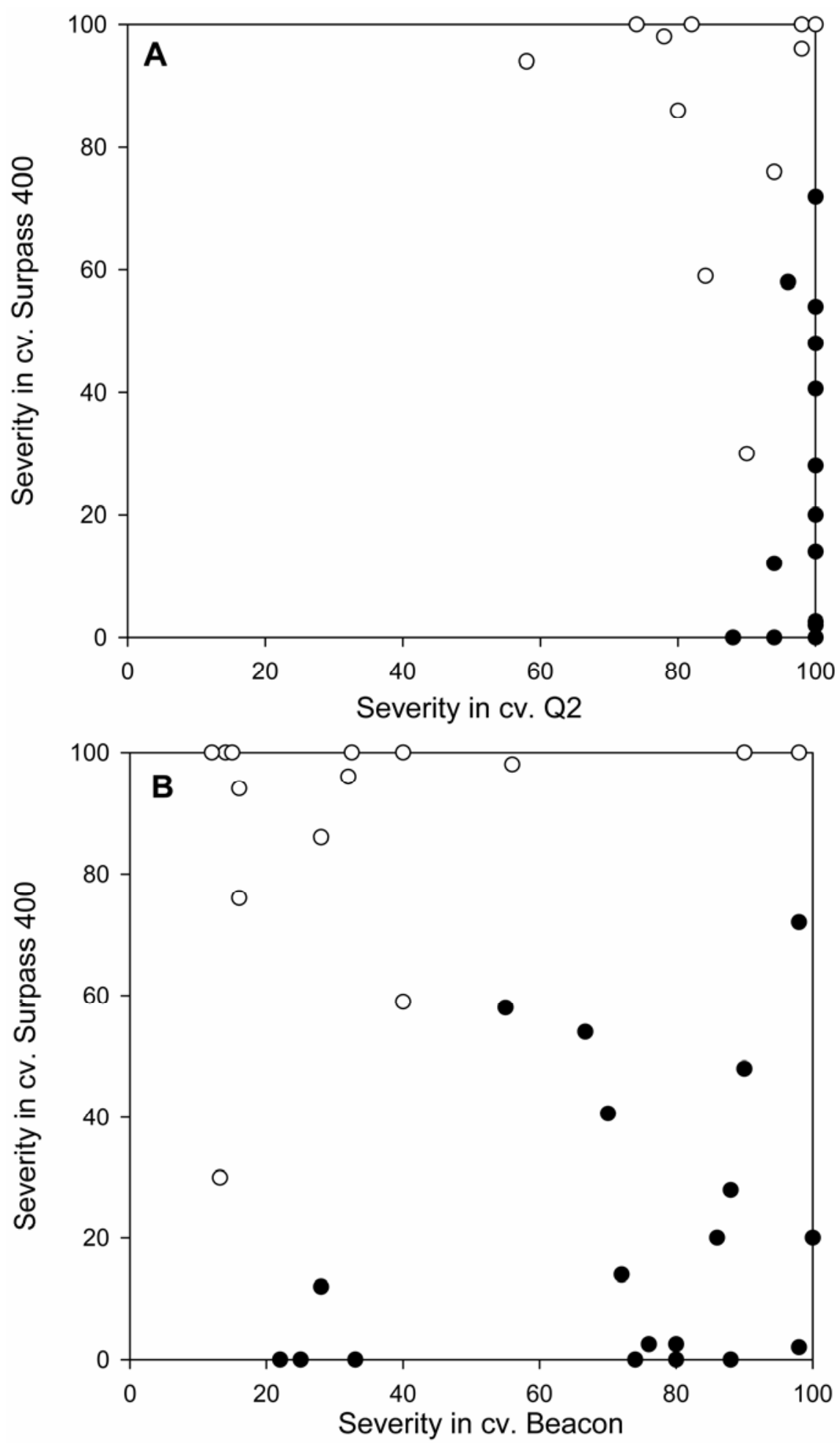

Fig. 4. Severity of blackleg in the stem at plant maturity caused by 33 individual isolates collected from the stubble of a cultivar with polygenic (-) or Brassica rapa subsp. sylvestris-derived resistance (O) and inoculated onto different cultivars. Each isolate was inoculated onto cv. Surpass 400; A, cv. Q2, the highly susceptible control; and $\mathbf{B}$, the moderately resistant polygenic cv. Beacon.

duction system (24). L. maculans exhibits a mixed mode of reproduction, which may have contributed to the increase in frequency of isolates able to overcome the sylvestris-derived resistance. Sexual reproduction may have increased the proportion of selected isolates in the population through recombination, with the resultant ascospores infecting newly sown crops. Although the role of pycnidiospores in relation to the development of blackleg epidemics is thought to be minimal (34), the asexual multiplication phase may increase to a high level the frequency of isolates in the population able to overcome the resistance through clonal reproduction. Selection combined with the mixed mode of reproduction proves a more probable explanation of the increased frequency of isolates able to cause disease on cultivars with sylvestris-derived resistance than the introduction of these isolates via transmission on seed. The spread of $L$. maculans via infected seed is extremely rare because the majority of canola seed sold commercially in Australia is now treated with a fungicidal seed dressing. Barrins (4) did not find any seed infected with $L$. maculans after testing approximately 28,000 seed untreated with fungicide from 14 different grain depots from across Victoria and Western Australia in 2001.

The frequency of isolates able to infect cultivars with sylvestris-derived resistance and subsequent levels of disease recorded in the survey of commercial crops differed between states. The frequency of highly virulent isolates increased in both Victoria and South Australia from 2002 to 2003, but did not change in New South Wales. In contrast, the level of disease observed in field surveys was much greater in South Australia than in either Victoria or New South Wales. One possible explanation for the high frequency of virulent isolates collected from Victoria is that the stubble was collected from trial sites where canola lines with sylvestris-derived resistance had been grown in close proximity for a number of years. Hence, the selection on the population at these sites may not reflect the larger L. maculans population in Victoria, where low disease levels were recorded in field surveys in 2003 and 2004. Another explanation for the high disease levels in South Australia may be that farmers adopted the cultivars with sylvestrisderived resistance immediately following their release, much more quickly than they were adopted by farmers in other states. The host specificity in the stem canker tests of isolates collected in 2004 and the high disease levels recorded in the cultivar with sylvestris-derived resistance compared with the polygenic cultivar at many South Australian sites in 2004 is consistent with extremely strong selection pressure placed on the L. maculans population due to the wide-scale use of cultivars with sylvestris-derived resistance. 
L. maculans has a number of characteristics that are indicative of a pathogen with a high risk of overcoming resistance genes. McDonald and Linde $(23,24)$ proposed that a high evolutionary potential of a pathogen is associated with a mixed reproduction system, a high potential for genotype flow (i.e., long-distance dispersal), and a large population size. These, in combination with the widespread use of a major gene for resistance, would create a situation in which the pathogen was highly likely to overcome the resistance. L. maculans has a large population size with airborne ascospores and reproduces both sexually on stubble and asexually within the host crop. This high evolutionary potential is supported by the findings that Australian populations of $L$. maculans have high levels of gene and genotypic diversity (H. L. Hayden and B. J. Howlett, unpublished). Another example of a fungal pathogen with high evolutionary potential overcoming host resistance is Mycosphaerella graminicola (anamorph Septoria tritici), a foliar pathogen of wheat. Within 5 years of the release in Oregon of a cultivar with high resistance (cv. Gene), isolates were identified that could specifically overcome this resistance (7). Despite the reduction in commercial production of $\mathrm{cv}$. Gene, these isolates have persisted in the population. M. graminicola has a high degree of gene and genotypic diversity and a lifecycle very similar to that of $L$. maculans, with sexual recombination occurring on infected debris, airborne dispersal of sexual spores, and asexual multiplication within the crop (6).

Host plant resistance, in combination with cultural practices, has been the strategy for controlling L. maculans in Australia. However, the dramatic breakdown of major gene resistance presented here highlights the need for strategies to deploy resistance sources so that they are effective for as long as possible. McDonald and Linde (23) suggest that, in situations where the probability of resistance breakdown is high, breeders should focus on the use of quantitative (polygenic) resistance, renewed regularly. Although this has been a relatively successful strategy for the Australian canola industry to date, cultivars with polygenic resistance can still incur significant yield loss in high disease situations and erosion of resistance over time.

It is assumed that the useful life of a major gene for resistance ends once it has been overcome by a pathogen. However, Rouxel et al. (29) found the avirulence gene, AvrLm4, in over $30 \%$ of French isolates after it previously was thought to be very rare or absent in France. If this increase coincided with the withdrawal of cultivars harboring the corresponding resistance gene $R \operatorname{lm} 4$, this finding suggests that a fitness deficit may be associated with the avrLm4 allele. The increase in AvrLm4-bearing isolates raises the pros- pect that resistance genes that previously had been overcome could be redeployed in the future. The current situation on the Lower Eyre Peninsula in which cultivars with sylvestris-derived resistance are no longer being grown and the high frequency of isolates with the ability to overcome the sylvestris-derived resistance provides an excellent long-term opportunity to understand the evolutionary forces involved in shaping the L. maculans populations in Australia.

\section{ACKNOWLEDGMENTS}

This research was funded by the Grains Research and Development Corporation, Australia. We thank A. Whitten and E. Crozier at the School of Botany, the University of Melbourne, and S. Hely, J. Graham, and G. Howe at CSIRO Plant Industry, Canberra, for technical help; and M. Uttley of Pacific Seeds and G. Braun of PIRSA for invaluable help in locating fields for the survey.

\section{LITERATURE CITED}

1. Ansan-Melayah, D., Balesdent, M. H., Delourme, R., Pilet, M. L., Tanguy, X., Renard, M., and Rouxel, T. 1998. Genes for racespecific resistance against blackleg disease in Brassica napus L. Plant Breed. 117:373-378.

2. Balesdent, M. H., Attard, A., Ansan-Melayah, D., Delourme, R., Renard, M., and Rouxel, T. 2001. Genetic control and host range of avirulence toward Brassica napus cultivars Quinta and Jet Neuf in Leptosphaeria maculans. Phytopathology 91:70-76.

3. Ballinger, D., and Salisbury, P. 1996. Seedling and adult plant evaluation of race variability in Leptosphaeria maculans on Brassica species in Australia. Aust. J. Exp. Agric. 36:485-488.

4. Barrins, J. M. 2002. A population genetics study of the canola pathogen Leptosphaeria maculans. In: School of Botany. The University of Melbourne, Melbourne, Australia.

5. Brun, H., Levivier, S., Somda, I., Ruer, D., Renard, M., and Chevre, A. M. 2000. A field method for evaluating the potential durability of new resistance sources: Application to the Leptosphaeria maculans-Brassica napus pathosystem. Phytopathology 90:961-966.

6. Chen, R. S., Boeger, J. M., and McDonald, B. A. 1994. Genetic stability in a population of a plant pathogenic fungus over time. Mol. Ecol. 3:209-218.

7. Cowger, C., Hoffer, M. E., and Mundt, C. C. 2000. Specific adaptation by Mycosphaerella graminicola to a resistant wheat cultivar. Plant Pathol. 49:445-451.

8. Crouch, J. H., Lewis, B. G., and Mithen, R. F. 1994. The effect of A-genome substitution on the resistance of Brassica napus to infection by Leptosphaeria maculans. Plant Breed. 112:265-278.

9. Easton, A. 2004. Why blackleg is now able to attack BLT 9 varieties, and how to minimise the risks. Pages 157-158 in: GRDC Southern New South Wales Grains Research Update. Grains Research and Development Corp., Canberra, Australia.

10. Gugel, R. K., Séguin-Swartz, G., and Petrie, G. A. 1990. Pathogenicity of three isolates of Leptosphaeria maculans on Brassica species and other crucifers. Can. J. Plant Pathol. 12:75-82.

11. Hammond, K., Lewis, B., and Musa, T. 1985. A systemic pathway in the infection of oilseed rape plants by Leptosphaeria maculans. Plant Pathol. 34:557-565.

12. Hammond, K. E., and Lewis, B. G. 1987. Variation in stem infections caused by aggressive and non-aggressive isolates of Leptosphaeria maculans on Brassica napus var. oleifera. Plant Pathol. 36:53-65.

13. Howlett, B. J. 2004. Current knowledge of the interaction between Brassica napus and Leptosphaeria maculans. Can. J. Plant Pathol. 24:245-252

14. Koch, E., Song, K., Osborn, T. C., and Williams, P. H. 1991. Relationship between pathogenicity and phylogeny based on restriction fragment length polymorphism in Leptosphaeria maculans. Mol. Plant-Microbe Interact. 4:341-349.

15. Li, C. X., and Cowling, W. A. 2003. Identification of a single dominant allele for resistance to blackleg in Brassica napus 'Surpass 400'. Plant Breed. 122:485-488.

16. Li, H., Barbetti, M., and Sivasithamparam, K. 2003. Responses of Brassica napus cultivars to Leptosphaeria maculans field isolates from Western Australia. Brassica 5:25-34.

17. Li, H., Barbetti, M., and Sivasithamparam, K. 2005. Hazard from reliance on cruciferous hosts as sources of major gene-based resistance for managing blackleg (Leptosphaeria maculans) disease. Field Crop Res. 91:185-198.

18. Li, H., Damour, L., Sivasithamparam, K., and Barbetti, M. 2004. Increased virulence and physiological specialization among Western Australian isolates of Leptosphaeria maculans breaking down existing single dominant genebased resistance in six cultivars of Brassica napus. Brassica 6:1-6.

19. Li, H., Sivasithamparam, K., and Barbetti, M J. 2003. Breakdown of a Brassica rapa subsp sylvestris single dominant blackleg resistance gene in B. napus rapeseed by Leptosphaeria maculans field isolates in Australia. Plant Dis. 87:752.

20. Marcroft, S. J., Purwantara, A., Salisbury, P. A., Potter, T. D., Wratten, N., Khangura, R., Barbetti, M. J., and Howlett, B. J. 2002. Reaction of a range of Brassica species under Australian conditions to the fungus, Leptosphaeria maculans, the causal agent of blackleg. Aust. J. Exp. Agric. 42:587-594.

21. Marcroft, S. J., Sprague, S. J., Pymer, S. J., Salisbury, P. A., and Howlett, B. J. 2004. Crop isolation, not extended rotation length, reduces blackleg (Leptosphaeria maculans) severity of canola (Brassica napus) in south-eastern Australia. Aust. J. Exp. Agric. 44:601-606.

22. Marcroft, S. J., Sprague, S. J., Salisbury, P. A. and Howlett, B. J. 2004. Potential for using host resistance to reduce production of pseudothecia and ascospores of Leptosphaeria maculans, the blackleg pathogen of Brassica napus. Plant Pathol. 53:468-474.

23. McDonald, B. A., and Linde, C. 2002. Pathogen population genetics, evolutionary potential, and durable resistance. Annu. Rev. Phytopathol. 40:349-379.

24. McDonald, B. A., and Linde, C. 2002. Pathogen population genetics and the durability of disease resistance. Euphytica 124:163-180.

25. Pang, E. C. K., and Halloran, G. M. 1996. The genetics of blackleg [Leptosphaeria maculans (Desm) Ces et De Not] resistance in rapeseed (Brassica napus L.) 2. Seedling and adult plant resistance as quantitative traits. Theor. Appl. Gen. 93:941-949.

26. Payne, R. W., Lane, P. W., Baird, D. B., Harding, S. A., Bicknell, K. E., Morgan, G. W. Murray, D. A., Thompson, R., Todd, A. D., Tunnicliffe, W. G., Webster, R., Welham, S. J., and White, R. P. 1995. GENSTAT 5 Release 3.2 Reference Manual. Clarendon Press, Oxford, UK

27. Purwantara, A., Salisbury, P. A., Burton, W. A., and Howlett, B. J. 1998. Reaction of Brassica juncea (Indian mustard) lines to Australian isolates of Leptosphaeria maculans under glasshouse and field conditions. Eur. J. Plant Pathol. 104:895-902.

28. Rimmer, S. R., and van den Berg, C. G. J. 1992. Resistance of oilseed Brassica spp. to 
blackleg caused by Leptosphaeria maculans. Can. J. Plant Pathol. 14:56-66.

29. Rouxel, T., Penaud, A., Pinochet, X., Brun, H., Gout, L., Delourme, R., Schmit, J., and Balesdent, M. H. 2003. A 10-year survey of populations of Leptosphaeria maculans in France indicates a rapid adaptation towards the Rlm 1 resistance gene of oilseed rape. Eur. J. Plant Pathol. 109:871-881.

30. Snowdon, R. J., Winter, H., Diestel, A., and Sacristan, M. D. 2000. Development and characterisation of Brassica napus-Sinapis arvensis addition lines exhibiting resistance to Leptosphaeria maculans. Theor. Appl. Genet. 101:1008-1014.
31. Sosnowski, M. R., Scott, E. S., and Ramsey, M. D. 2004. Infection of Australian canola cultivars (Brassica napus) by Leptosphaeria maculans is influenced by cultivar and environmental conditions. Australas. Plant Pathol. 33:401-411.

32. Sun, P., Fitt, B. D. L., Steed, J. M., Underwood, C. T., and West, J. S. 2001. Factors affecting development of Phoma canker (Leptosphaeria maculans) on stems of winter oilseed rape (Brassica napus) in southern England. Ann. Appl. Biol. 139:227-242.

33. U, N. 1935. Genome analysis in Brassica with special reference to the experimental formation of Brassica napus and particular mode of fer- tilization. Jpn. J. Bot. 7:389-452.

34. West, J. S., Kharbanda, P. D., Barbetti, M. J., and Fitt, B. D. L. 2001. Epidemiology and management of Leptosphaeria maculans (Phoma stem canker) on oilseed rape in Australia, Canada and Europe. Plant Pathol. 50:10-27.

35. Yu, F. Q., Lydiate, D. J., and Rimmer, S. R 2004. Identification and mapping of a third blackleg resistance locus in Brassica napus derived from B. rapa subsp. sylvestris. In: Plant Anim. Genome XII Conf. San Diego, CA.

36. Zhu, B., and Rimmer, S. R. 2003. Inheritance of resistance to Leptosphaeria maculans in two accessions of Brassica napus. Can. J. Plant Pathol. 25:98-103. 